\title{
Pengendali Kecepatan pada Alat Sentrifugasi Menggunakan Metode Logika Fuzzy
}

\author{
Garudio Kusuma Aji, Djoko Purwanto dan Muhammad Rivai \\ Departemen Teknik Elektro, Fakultas Teknologi Elektro, Institut Teknologi Sepuluh Nopember (ITS) \\ e-mail:djoko@ee.its.ac.id,muhammad_rivai@ee.its.ac.id
}

\begin{abstract}
Abstrak-Kehandalan alat sentrifugasi yang banyak digunakan oleh para pengusaha Virgin Coconut Oil (VCO) saat ini masih terbilang rendah. Alat sentrifugasi yang ada saat ini cenderung hanya diperuntukkan dalam proses pembuatan VCO dengan pemerasan santantanpa penambahan air, bukan untuk santan dengan penambahan air. Pada penelitian ini telah dirancang dan dibuat sistem pengendali kecepatan pada alat sentrifugasi dengan metode logika fuzzy untuk meningkatkan kehandalan alat sentrifugasi dalam proses pembuatan VCO, baik tanpa penambahan air maupun dengan penambahan air. Sistem ini dirancang agar menyesuaikan kecepatan sentrifugasi berdasarkan kekentalan atau konsentrasi santan serta durasi waktu proses. Sensor kecepatan yang terdapat pada alat sentrifugasi ini memiliki tingkat error mencapai $1,52 \%$. Logika fuzzy mampu mengendalikan kecepatan sentrifugasi sesuai dengan set point. Pada kondisi tanpa beban, settling time terbaik dari kontroler logika fuzzy pada set point 400 dan $800 \mathrm{rpm}$, dengan waktu 30 detik. Sedangkan pada kondisi berbeban, settling time terbaik terjadi pada set point $600 \mathrm{rpm}$, dengan waktu 30 detik. Diharapkan dengan adanya sistem ini mampu meningkatkan keandalan alat sentrifugasi yang sudah ada.
\end{abstract}

Kata Kunci-Alat Sentrifugasi, Kekentalan, Logika Fuzzy, VCO.

\section{PENDAHULUAN}

$\mathrm{A}$ LAT sentrifugasi adalah suatu alat pemisah yang memanfaatkan perbedaan efek gaya sentrifugal pada setiap molekul senyawa penyusun suspensi dari gerak putar.

Gaya sentrifugal adalah gaya semu yang mendorong benda menjauhi titik pusat putar yang timbul pada suatu benda yang bergerak berputar pada kerangka non-inersia. Kerangka noninersia pada alat sentrifugasi adalah botol tempat suspensi ditempatkan, dimana botol menjaga agar suspensi tidak tumpah tetapi tidak mempertahankan posisi molekul-molekul senyawa penyusun suspensi. Efek gaya sentrifugal akan mendorong setiap molekul-molekul menjauhi titik pusat putar [1].

Dalam bidang industri UMKM, alat sentrifugasi digunakan pada proses pembuatan Virgin Coconut Oil(VCO).VCO adalah minyak kelapa yang diproses dengan sedikit pemanasan. Terdapat dua metode pemisahan dalam pembuatan VCO, yaitu metode pendiaman dan sentrifugasi. Pada metode pendiaman, santan didiamkan dengan memanfaatkan efek gaya gravitasi. Sedangkan pada metode sentrifugasi, santan dimasukkan dalam wadah alat sentrifugasi dengan memanfaatkan efek gaya sentrifugal. Penggunaan alat sentrifugasi akan mempercepat proses pemisahan, serta memperkecil potensi kerusakan minyak selama proses pemisahan.

Alat pemisah atau sentrifugasiyang banyak digunakan oleh para pengusaha VCO belum bisa efisien dari sisi kecepatan sentrifugasi. Spesifikasi kecepatan putar sentrifugasi yang didasarkan pada spesifikasi kecepatan putar motor bukanlah cara yang tepat. Karena besar massa atau berat beban yang diputar motor saat proses sentrifugasi akan mempengaruhi kecepatan putar motor. Kecepatan motor akan turun sebanding dengan penambahan beban yang diputarnya.

Selain itu, alat sentrifugasi konvensional berputar dengan kecepatan penuh dari awal sampai dengan akhir proses, tanpa ada penyesuaian kecepatan dengan kondisi suspensi santan yang dipisahkan. Kondisi yang dimaksudkan diantaranya:

1. kondisi suspensi santan masih tercampur,

2. kondisi suspensi santan sudah mulai terpisah,

3. kondisi suspensi santan sudah terpisah,

4. kondisi suspensi santan sudah banyak yang terpisah,

5. kondisi suspensi santan sudah mencapai titik jenuh pemisahan,

Sebagai contoh pada saat motor berada pada kecepatan penuh, namun kondisi santan sudah mencapai titik jenuh, maka proses pemisahan tidak efisien dikarenakan efek gaya sentrifugal yang ditimbulkan motor sudah tidak berpengaruh pada suspensi santan.

Penambahan kontroler pengendali kecepatan yang mampu menyesuaikan dengan kondisi suspensi diharapkan mampu meningkatkan efisiensi alat sentrifugasi. Kontroler logika fuzzy adalah salah satu metode kontroler yang sedang berkembang saat ini. Logika fuzzy merupakan metode kontroler yang memungkinkan proses secara penalaran bahasa, sehingga dalam perancangan sistem kendali atau kontrol tidak memerlukan persamaan matematik dari objek yang akan dikendalikan [2]. Kontroler logika fuzzy akan diimplementasikan dalam pengendali kecepatan alat sentrifugasi untuk meningkatkan efisiensi pemisahan VCO dari suspensi santan

Pada penelitian ini telah dirancang alat sentrifugasi yang dilengkapi dengan pengendali kecepatan yang bertujuan untuk meningkatkan efisiensi alat sentrifugasi sesuai dengan kondisi dari suspensi santan dalam waktu tertentu.

\section{METODE PENELITIAN}

Alat sentrifugasi yang dirancang pada penelitian ini dilengkapi dengan sistem kontroler logika fuzzy. Konsentrasi dan waktu proses sentrifugasi dari suspensi menjadi masukan logika fuzzy kecepatan set point sentrifugasi. Nilai kecepatan set point dari logika fuzzy pertama akan diakusisi oleh logika fuzzy kedua, dimana nilai set point akan menjadi nilai parameter untuk kecepatan putar aktual alat sentrifugasi. 
Kecepatan putar aktual diperoleh dari akusisi data sensor kecepatan. Perbedaan nilai dari kecepatan set point dan kecepatan aktual yaitu error, dan perubahan error setiap perulangan sistem yaitu deltaError, akan menjadi masukan bagi logika fuzzy kestabilan kecepatan. Kedua parameter ini akan diproses untuk mendapatkan nilai PWM yang tepat untuk mencapai set point [3].

\section{A. Antarmuka}

Gambar 1 menunjukkan skema sistem antarmuka pada alat sentrifugasiyang terdiri dari keypad $4 \times 3$ sebagai perangkat masukan, Arduino Uno sebagai perangkat mikrokontroler, dan LCD 16x2 sebagai perangkat display. Komunikasi antar perangkat menggunakan metode komunikasi I2C. Metode komunikasi $\mathrm{I} 2 \mathrm{C}$ dipilih dikarenakan keterbatasan port $\mathrm{I} / \mathrm{O}$ pada Arduino Uno.

\section{B. Logika Fuzzy Set Point Kecepatan Sentrifugasi}

Data karakterisasi variabel konsentrasi, waktu, dan kecepatan menjadi acuan dalam fuzzifikasi dan rule base dari logika fuzzy. Nilai konsentrasi dan waktu menjadi variabel masukan untuk menentukan variabel kecepatan sentrifugasi, ditunjukkan pada Gambar 2. Selama proses sentrifugasi, keypad dinonaktifkan.

Fungsi keanggotaan yang digunakan untuk fuzzifikasi seluruh variabel masukan, konsentrasi dan proses waktu adalah kurva bentuk "bahu", ditunjukkan pada Gambar 3 dan 4. Pemilihan representasi bentuk bahu ini dikarenakan kemudahan pengaplikasian dalam program mikrokontroler [3][4][5][6][7], dan [8].

Mamdani adalah metode inferensi yang digunakan pada logika fuzzy set point kecepatan sentrifugasi. Metode Min Operation adalah rule evaluation yang digunakan untuk menentukan besar nilai derajat keanggotaan dari kedua variabel masukan disetiap periode perulangan sistem.

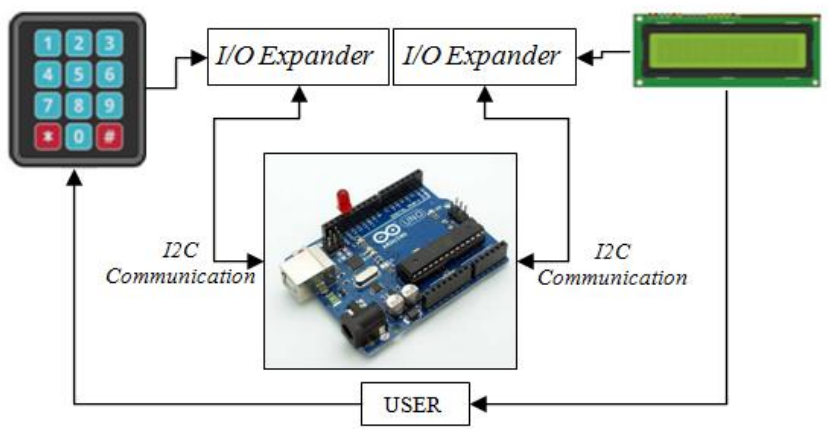

Gambar 1. Skema sistem antarmuka alat sentrifugasi.

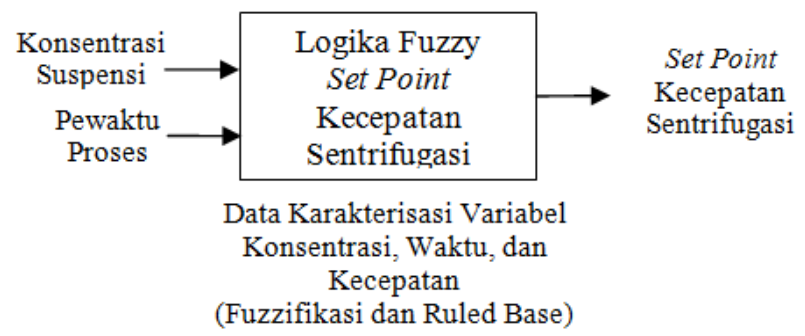

Gambar 2. Diagram blok sistem logika fuzzy set point kecepatan sentrifugasi.

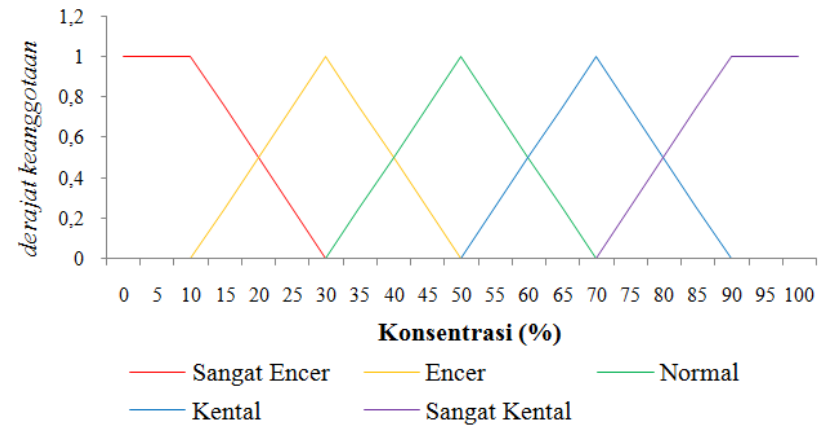

Gambar 3. Kurva keanggotaan variabel masukan konsentrasi.

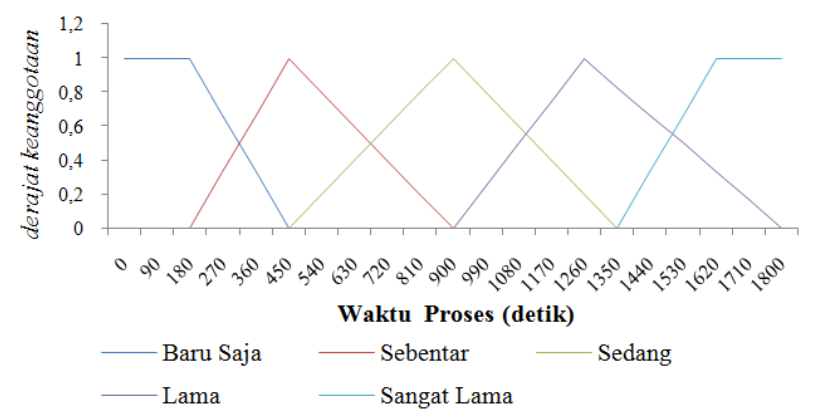

Gambar 4. Kurva keanggotaan variabel masukan waktu proses.

Tabel 1.

Rule base logika fuzzy set point kecepatan sentrifugasi.

\begin{tabular}{|l|c|c|c|c|c|}
\hline Waktu Proses & $\begin{array}{c}\text { Baru } \\
\text { Saja }\end{array}$ & Sebentar & Sedang & Lama & $\begin{array}{c}\text { Sangat } \\
\text { Lama }\end{array}$ \\
\cline { 1 - 6 } Sonsentrasi & 400 & 200 & 200 & 0 & 0 \\
\hline Rendah & 400 & 400 & 200 & 200 & 0 \\
\hline Normal & 600 & 400 & 400 & 200 & 0 \\
\hline Tinggi & 800 & 600 & 400 & 400 & 0 \\
\hline Sangat Tinggi & 800 & 800 & 600 & 400 & 0 \\
\hline
\end{tabular}

Tabel 1 adalah ruled baseouput logika fuzzy set point kecepatan sentrifugasi. Metode Max Function adalah rule aggregation yang digunakan untuk menentukan besar OutputSet Point kecepatan dari Rule Base yang telah dirancang. Rule base akan disesuaikan kembali dengan data karakterisasi suspensi santan.Metode center of gravity digunakan untuk defuzzifikasi dalam menentukan set point kecepatan sentrifugasiyang dibutuhkan alat ini untuk memisahkan suspensi disetiap periode perulang sistem [9].

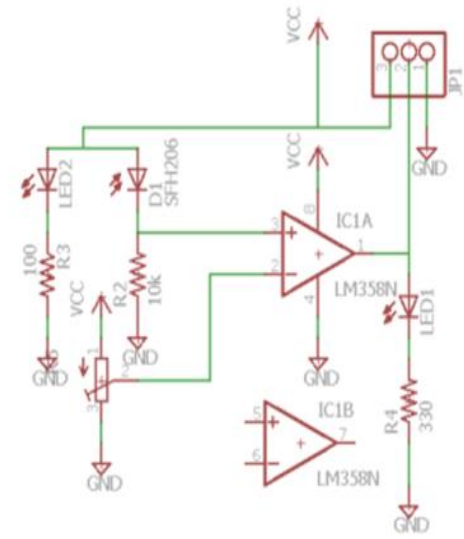

Gambar 5. Skematik sensor encoder. 


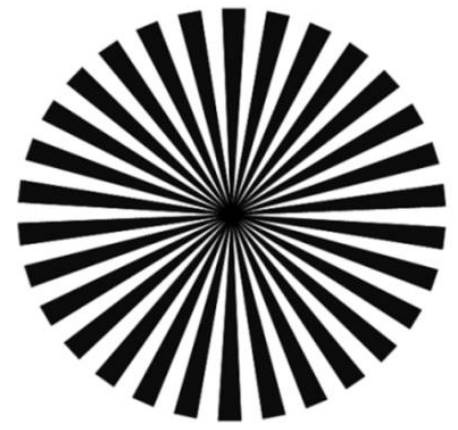

Gambar 6. Skema "piring" alat sentrifugasi.

\section{Sensor Kecepatan Sentrifugasi}

Sensor kecepatan sentrifugasi pada penelitian ini dirancang berbasiskan sensor increment encoder, ditunjukkan pada Gambar 5. Perangkat yang menyusun subsistem Sensor Kecepatan Sentifugasi diantaranya: Sensor Increment Encoder "piring" sentrifugasi seperti yang ditunjukkan pada Gambar 6, dan Arduino Uno. Jumlah pulsa increment dalam satu putaran sentrifugasi adalah 30 pulsa bernilai "HIGH" dan 30 pulsa benilai "LOW". Kecepatan putar sentrifugasi dapat diperoleh dengan menggunakan persamaan:

$$
\text { Kecepatan }_{\text {Angular }}=\text { Frekuensi Keluaran } \cdot 2(\mathrm{rpm})
$$

Dengan setiap periode perulangan sistem proses adalah 0,1 detik atau $10 \mathrm{~Hz}$. Besar kecepatan sentrifugasi dalam setiap perulangan sistem adalah:

$$
\text { Kecepatan Sentrifugasi } i_{\text {sistem }}=\text { Jumlah Pulsa } \cdot 20(\mathrm{rpm})
$$

\section{Logika Fuzzy Kestabilan Kecepatan Sentrifugasi}

Hasil keputusan logika fuzzySet Point Kecepatan Sentrifugasi menjadi variabel parameter pada Kontroler logika fuzzy Kestabilan Kecepatan Sentrifugasi yang harus dipenuhi [10]. Variabel yang masuk pada logika fuzzy Kestabilan Kecepatan Sentrifugasi adalah error dan deltaError yang dinyatakan:

$$
\begin{gathered}
\operatorname{Error}(t)=\text { Kecepatan Set Point }(t)-\text { Kecepatan Aktual }(t) \\
\text { deltaError }(t)=\operatorname{Error}(t)-\operatorname{Error}(t-1)
\end{gathered}
$$

Data Karakterisasi Kecepatan Motor DC

(Fuzzifikasi dan Ruled Base)

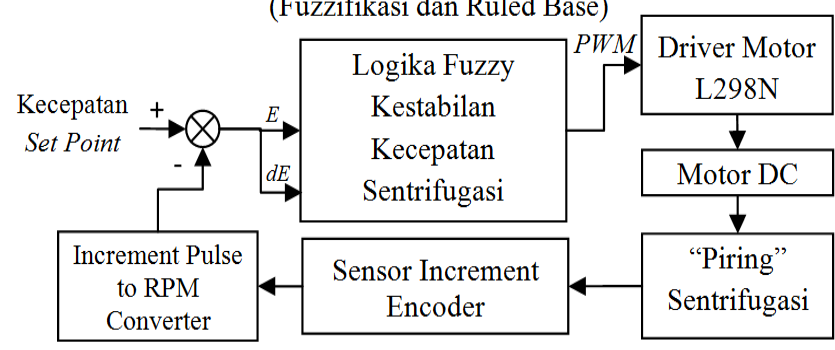

Gambar 7. Skema diagram blok logika fuzzy kestabilan kecepatan sentrifugasi.

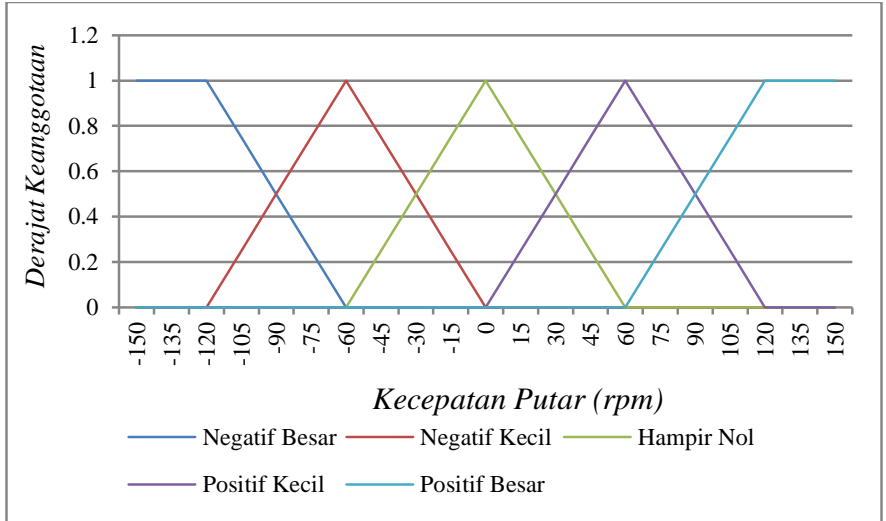

Gambar 8. Kurva keanggotaan variabel masukan error.

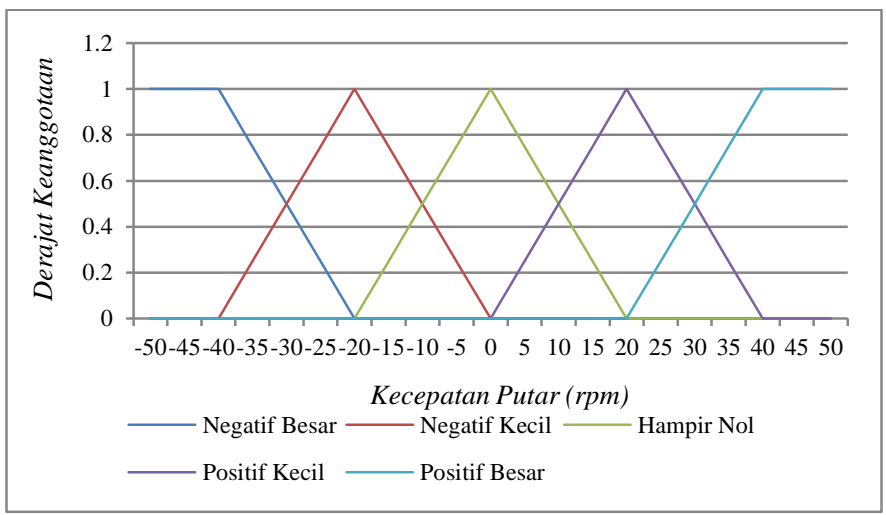

Gambar 9. Kurva keanggotaan variabel masukan deltaError.

Variabel masukan pada Logika Fuzzy Kestabilan Kecepatan Sentrifugasi adalah Error dan deltaError, ditunjukkan pada Gambar 8 dan 9. Nilai Error diperoleh dari perbedaan nilai kecepatan Set Point dengan kecepatan aktual. Sementara nilai deltaError diperoleh dari perbedaan error periode sistem saat ini dengan error periode sistem sebelumnya. Tabel 2 adalah rule baseyang digunakan pada logika fuzzy kestabilan kecepatan sentrifugasi. Metode defuzzifikasi centre of gravity digunakan untuk menentukan Output koreksi duty cycle dari PWM agar kecepatan aktual sentrifugasi mencapai kecepatan set point.

$$
\text { Center Of Gravity }=\frac{\sum_{x=a}^{b} \mu_{A}(x) x}{\sum_{x=a}^{b} \mu_{A}(x)}
$$

Tabel 2.

Rule base logika fuzzy kestabilan kecepatan sentrifugasi.

\begin{tabular}{|c|c|c|c|c|c|}
\hline Error & $\begin{array}{c}\text { Negatif } \\
\text { Besar }\end{array}$ & $\begin{array}{c}\text { Negatif } \\
\text { Kecil }\end{array}$ & $\begin{array}{c}\text { Hampir } \\
\text { Nol }\end{array}$ & $\begin{array}{c}\text { Positif } \\
\text { Kecil }\end{array}$ & $\begin{array}{c}\text { Positif } \\
\text { Besar }\end{array}$ \\
\hline Negattatror Besar & -6 & -3 & -3 & 0 & 3 \\
\hline Negatif Kecil & -6 & -3 & 0 & 0 & 6 \\
\hline Hampir Nol & -6 & 0 & 0 & 0 & 6 \\
\hline Positif Kecil & -6 & 0 & 0 & 3 & 6 \\
\hline Positif Besar & -3 & 0 & 3 & 3 & 6 \\
\hline
\end{tabular}

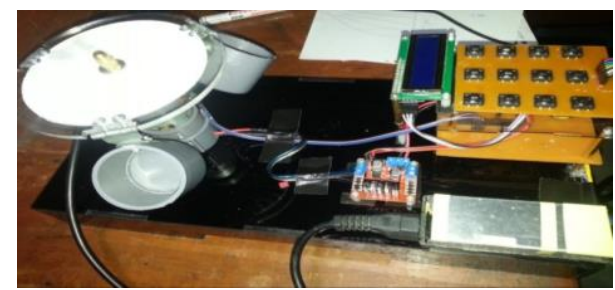

Gambar 10. Bentuk realisasi alat sentrifugasi. 


\section{HASIL DAN DISKUSI}

\section{A. Pengujian Kecepatan Maksimal Alat Sentrifugasi}

Pengujian dilakukan dengan menyalakan alat sentrifugasi dan menghubungkan pin enable B dengan pin jumper. Dengan menghubungkan pin enable $\mathrm{B}$, maka motor DC akan berputar dengan kecepatan penuh. Pengukuran dilakukan dengan menggunakan tachometer digital tipe DT-2234C $\mathrm{C}^{+}$. Hasil pengujian kecepatan ini ditunjukkan pada Tabel 3 dan 4.

Dari kedua hasil pengujian kecepatan maksimal alat sentrifugasi ini menunjukkan bahwa pembebanan pada alat sentrifugasi mempengaruhi kecepatan sentrifugasi. Rata-rata kecepatan sentrifugasi aktual tanpa beban adalah $1134,25 \mathrm{rpm}$, sedangkan saat berbeban adalah $931,75 \mathrm{rpm}$. Setelah pembebanan, kecepatan sentrifugasi turun 202,5 rpm.

Tabel 3.

Kecepatan maksimal alat sentrifugasi tanpa beban.

\begin{tabular}{|c|c|c|}
\hline No. & Pengambilan Ke- & DT-2234C \\
\hline 1 & 1 & 1139 \\
\hline 2 & 2 & 1137 \\
\hline 3 & 3 & 1132 \\
\hline 4 & 4 & 1129 \\
\hline \multirow{2}{*}{} & Rata-rata & 1134,25 \\
\cline { 2 - 3 }
\end{tabular}

Tabel 4.

Kecepatan maksimal alat sentrifugasi berbeban ( 3 x 66 gram).

\begin{tabular}{|c|c|c|}
\hline No. & Pengambilan Ke- & DT $-2234 C^{+},(\mathrm{rpm})$ \\
\hline 1 & 1 & 926 \\
\hline 2 & 2 & 931 \\
\hline 3 & 3 & 936 \\
\hline 4 & 4 & 934 \\
\hline \multirow{2}{*}{} & Rata-rata & 931,75 \\
\cline { 2 - 3 }
\end{tabular}

\section{B. Pengujian Sensor Kecepatan Sentrifugasi}

Pengujian dilakukan dengan melihat sinyal keluaran sensor increment encoder terhadap kecepatan putar "piring" sentrifugasi pada tegangan tertentu. Sinyal keluaran sensor encoder ditampilkan pada osiloskop untuk melihat bentuk dan frekuensi pulsa yang dikeluarkan sensor increment encoder.

Dari data yang tertera pada Tabel 5 menunjukkan bahwa perubahan jumlah pulsa setiap detik yang dikeluarkan pada sensor increment encoder berbanding lurus dengan perubahan tegangan. Terdapat perbedaan hasil pembacaan antara sensor increment encoder dengan DT- $2234 \mathrm{C}^{+}$, dimana dari enam pengujian rata-rata perbedaan sebesar 31,67 rpm. Perbedaan tertinggi terdapat pada tegangan 6 volt yang mencapai $71 \mathrm{rpm}$, sedangkan perbedaan terkecil terdapat pada tegangan 15 volt yang hanya $1 \mathrm{rpm}$.

\section{Pengujian Duty Cycle Terhadap Sistem Penggerak Sentrifugasi}

Tabel 6 menunjukkan hasil pengujian pada sistem penggerak alat sentrifugasi. Pengujian ini bertujuan untuk melihat respon sistem penggerak alat sentrifugasi terhadap perubahan Duty Cycle PWM.

\section{Pengujian Logika Fuzzy Set Point Kecepatan Sentrifugasi}

Pengujian ini dilakukan untuk melihat respon sistem logika fuzzy dalam menetukan kecepatan set point terhadap beberapa level konsentrasi dengan durasi waktu proses tertentu.
Tabel 5 .

Sinyal Pulsa Keluaran Sensor Encoder

\begin{tabular}{|c|c|c|c|c|}
\multirow{2}{*}{ No. } & \multirow{2}{*}{$\begin{array}{c}\text { Tegangan } \\
\text { (Volt) }\end{array}$} & $\begin{array}{c}\text { Frekuensi } \\
(\mathrm{Hz})\end{array}$ & $\begin{array}{c}\text { Kecepatan Putar } \\
=\mathrm{f}^{*} 2,(\mathrm{rpm})\end{array}$ & $\mathrm{DT}^{2} 234 \mathrm{C}^{+}$ \\
\hline 1 & 3 & 173 & 346 & 356 \\
\hline 2 & 6 & 290 & 580 & 509 \\
\hline 3 & 9 & 403 & 806 & 819 \\
\hline 4 & 12 & 480 & 960 & 987 \\
\hline 5 & 15 & 568 & 1136 & 1135 \\
\hline 6 & 18 & 595 & 1190 & 1258 \\
\hline
\end{tabular}

Tabel 6.

Duty cycle terhadap sensor kecepatan.

\begin{tabular}{|c|c|c|c|c|}
\hline \multirow{2}{*}{ No. } & \multirow{2}{*}{$\begin{array}{c}\text { Duty Cycle } \\
(\%)\end{array}$} & \multicolumn{2}{|c|}{ Kecepatan (rpm) } & \multirow{2}{*}{$\begin{array}{c}\text { error } \\
(\%)\end{array}$} \\
\hline & & Sensor Kecepatan & DT-2234C & \\
\hline 1 & 10 & 266 & 262 & 1,52 \\
\hline 2 & 20 & 431,0175 & 415 & 3,85 \\
\hline 3 & 30 & 544,4385 & 510 & 6,75 \\
\hline 4 & 40 & 628,0350 & 609 & 3,12 \\
\hline 5 & 50 & 705,3508 & 675 & 4,49 \\
\hline 6 & 60 & 761,1052 & 730 & 4,26 \\
\hline 7 & 70 & 835,7894 & 775 & 7,84 \\
\hline 8 & 80 & 889,4385 & 812 & 9,53 \\
\hline 9 & 90 & 951,8596 & 840 & 13,31 \\
\hline
\end{tabular}

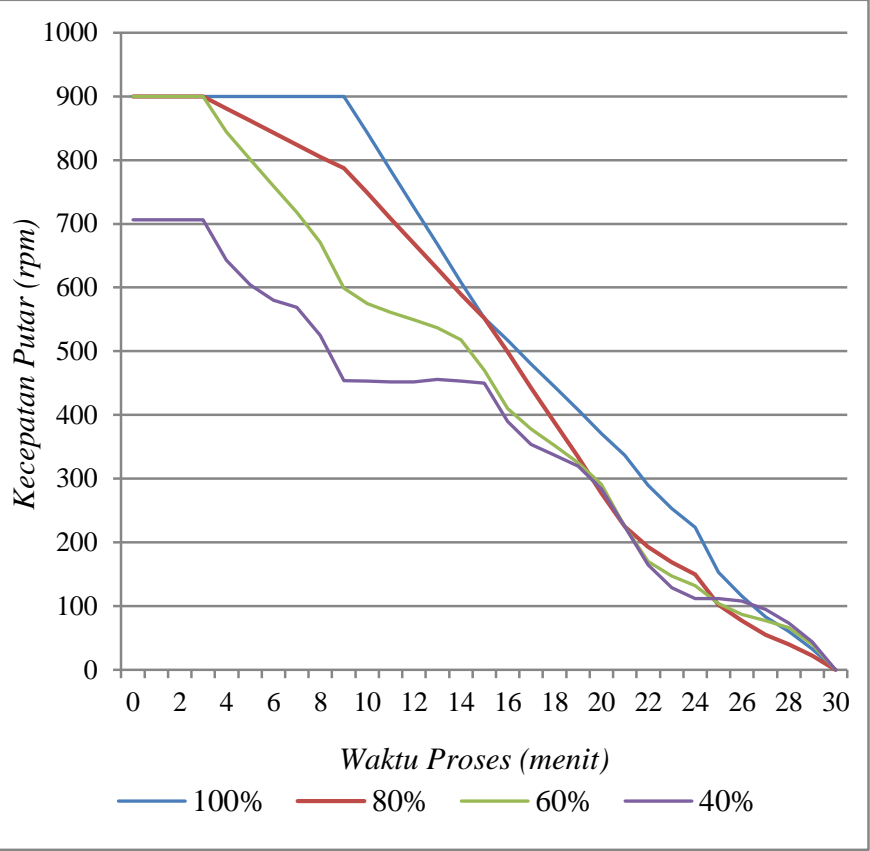

Gambar 11. Respon logika fuzzy set point kecepatan terhadap perubahan waktu proses pada beberapa tingkat konsentrasi.

Pada Gambar 11 menunjukkan bahwa logika fuzzy set point kecepatan sentrifugasimampu mengatur kecepatan sentrifugasi sesuai dengan perubahan variabel waktu proses. Untuk setiap konsentrasi santan memiliki pola respon yang berbeda-beda.

\section{E. Pengujian Logika Fuzzy Kestabilan Kecepatan Sentrifugasi}

Pada pengujian ini, logika fuzzy akan mendapat masukan variabel parameter berupa kecepatan set pointdan variabel feedback berupa kecepatan aktual. Variabel kecepatan set 
point bersifat tetap yang ditanamkan ke dalam program. Sedangkan kecepatan aktual didapatkan dari akuisisi data dari sensor kecepatan sentrifugasi.

1. Pengujian Tanpa Beban

Pengujian dilakukan dengan memberikan beberapa tingkat variabel parameter kecepatan set point. Gambar 12-15 menunjukkan grafik time response kontroler terhadap beberapa nilai kecepatan set point tanpa beban.

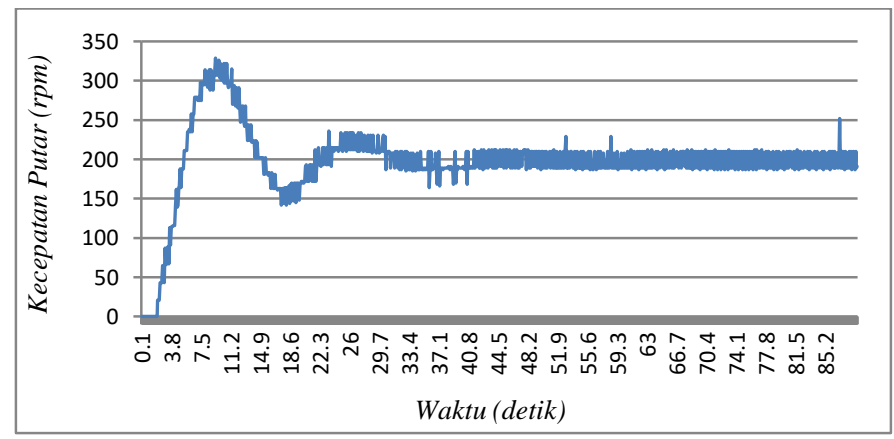

Gambar 12. Grafik time response pada set point 200 rpm tanpa beban.

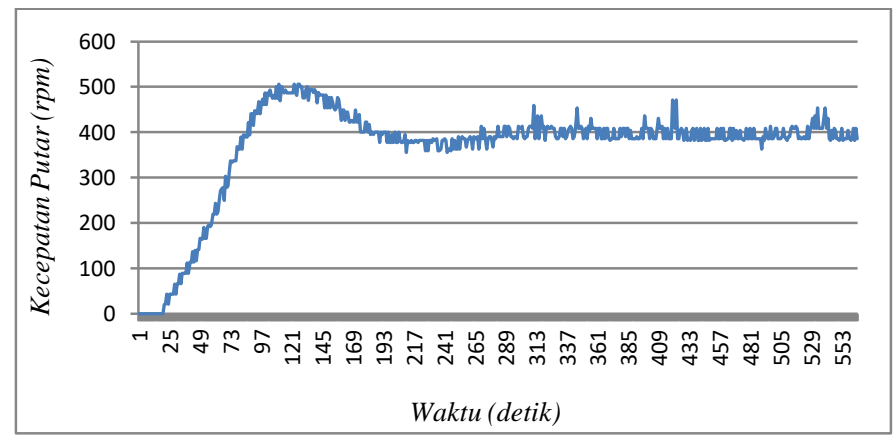

Gambar 13. Grafik time response pada set point 400 rpm tanpa beban.

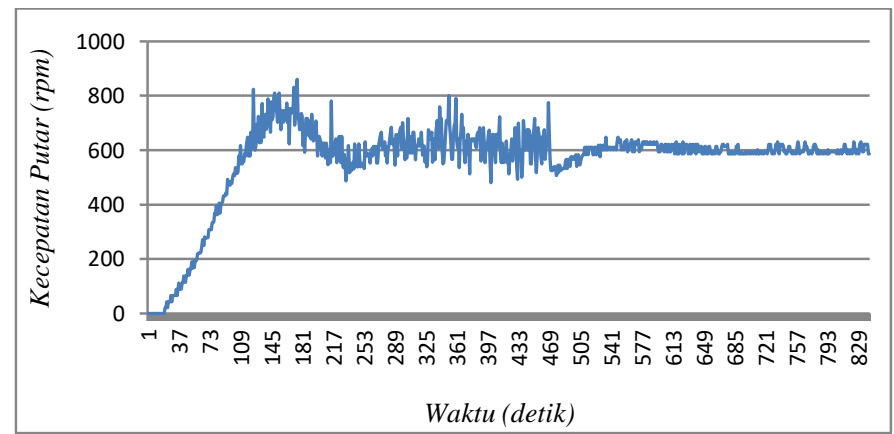

Gambar 14. Grafik time response pada set point 600 rpm tanpa beban.

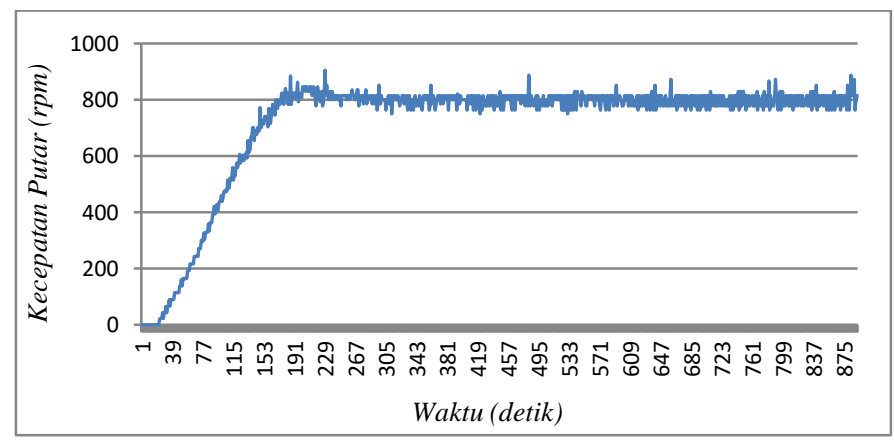

Gambar 15. Grafik time response pada set point 800 rpm tanpa beban.
2. Pengujian Berbeban

Perlakuan pada pengujian ini sama dengan pengujian tanpa beban, hanya yang membedakan pada pengujian ini adalah adanya beban yang harus diputar oleh alat sentrifugasi. Gambar 16-19 menunjukkan grafik time response kontroler terhadap beberapa nilai kecepatan set point berbeban.

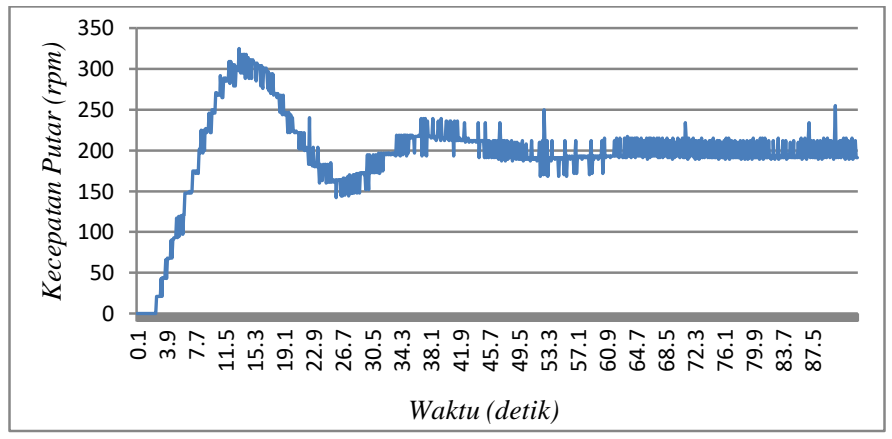

Gambar 16. Grafik time repons pada set point $200 \mathrm{rpm}$ berbeban.

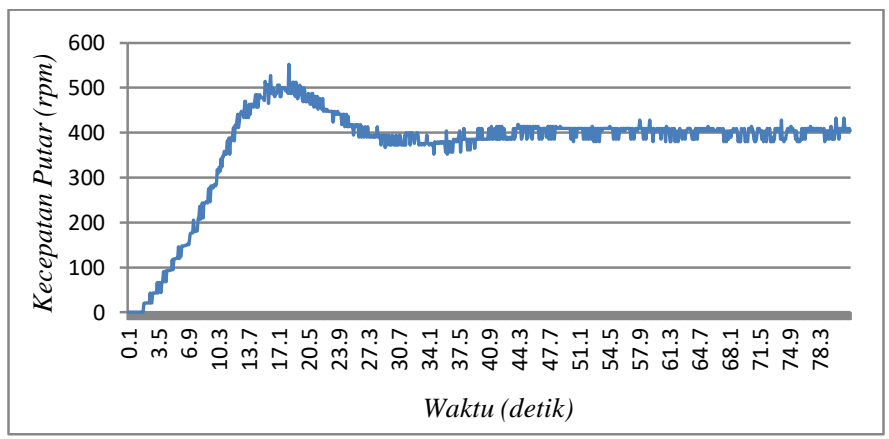

Gambar 17. Grafik time response pada set point $400 \mathrm{rpm}$ berbeban.

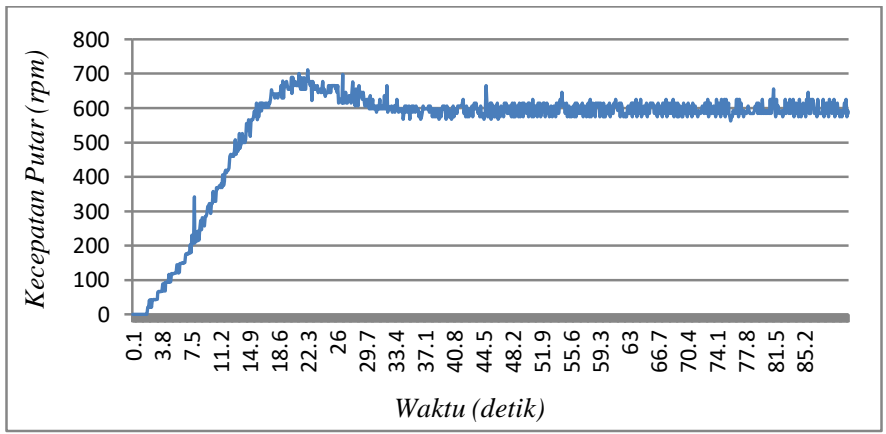

Gambar 18. Grafik time response pada set point $600 \mathrm{rpm}$ berbeban.

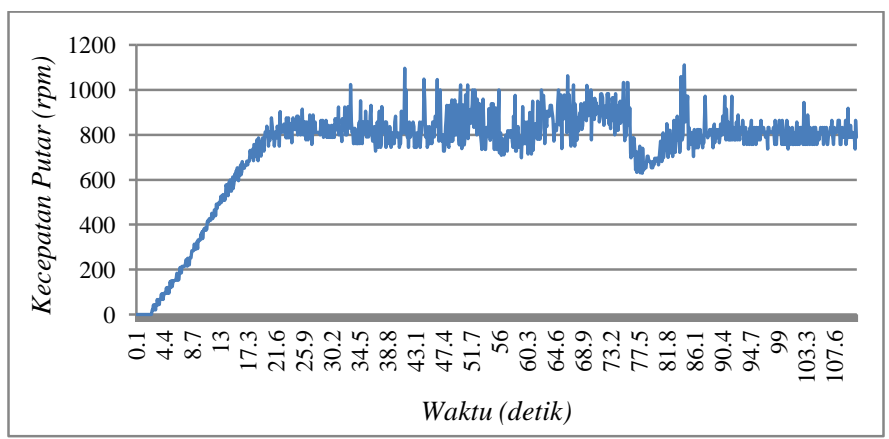

Gambar 19. Grafik time respons pada set point $800 \mathrm{rpm}$ berbeban. 
Bedasarkan data pada Tabel 7 menunjukkan bahwa pada kondisi tanpa beban, kontroler mampu mencapai keadaan settling time terbaik pada set point 400 dan $800 \mathrm{rpm}$ dengan waktu 30 detik. Pada kondisi berbeban, kontroler mencapai keadaan settling time terbaik pada set point $600 \mathrm{rpm}$ dengan waktu 35 detik.

Tabel 7.

Spesifikasi respon transien kontroler

\begin{tabular}{|c|c|c|c|c|c|c|}
\hline \multirow{4}{*}{ Kategori } & $\begin{array}{c}\text { Set } \\
\text { Point } \\
(\mathrm{rpm})\end{array}$ & $\begin{array}{c}\text { Time } \\
\text { Delay } \\
(s)\end{array}$ & $\begin{array}{c}\text { Rise } \\
\text { Time } \\
(s)\end{array}$ & $\begin{array}{c}\text { Peak } \\
\text { Time } \\
(s)\end{array}$ & $\begin{array}{c}\text { Over- } \\
\text { shoot } \\
(\%)\end{array}$ & $\begin{array}{c}\text { Settling } \\
\text { Time }(s)\end{array}$ \\
\hline \multirow{4}{*}{$\begin{array}{c}\text { Tanpa } \\
\text { Beban }\end{array}$} & 200 & 3,8 & 5,4 & 9,3 & 64,5 & 42 \\
\cline { 2 - 7 } & 400 & 5,9 & 8,7 & 11,1 & 26,5 & 30 \\
\cline { 2 - 7 } & 600 & 7,2 & 10,9 & 17,5 & 65 & 55 \\
\cline { 2 - 7 } & 800 & 9,1 & 16,8 & 18,6 & 10,5 & 30 \\
\hline \multirow{5}{*}{ Berbeban } & 200 & 5,2 & 7,1 & 13,3 & 62,5 & 43 \\
\cline { 2 - 7 } & 400 & 8 & 12 & 15 & 21,25 & 43 \\
\cline { 2 - 7 } & 600 & 9,6 & 15,8 & 20,2 & 15 & 35 \\
\cline { 2 - 7 } & 800 & 11 & 19,9 & 25,6 & 14,25 & 93 \\
\hline
\end{tabular}

\section{KESIMPULAN}

Pada penelitian ini telah dirancang dan dibuat sebuah alat sentrifugasi yang dilengkapi dengan sistem pengendali kecepatan. Sensor kecepatan yang terdapat pada alat sentrifugasi ini memiliki tingkat error mencapai $1,52 \%$. Logika fuzzy mampu menentukan set point kecepatan alat sentrifugasi berdasarkan perubahan waktu dan konsentrasi santan. Kontroler logika fuzzy mampu mengendalikan kecepatan sentrifugasi sesuai dengan set point. Pada kondisi tanpa beban,settling time terbaik dari kontroler logika fuzzy pada set point 400 dan $800 \mathrm{rpm}$, dengan waktu 30 detik. Sedangkan pada kondisi berbeban, settling time terbaik terjadi pada set point 600 rpm, dengan waktu 30 detik.

\section{DAFTAR PUSTAKA}

[1] T. Yuwono, Biologi Molekular. Jakarta: Erlangga, 2009.

[2] Kusumadewi, Aplikasi Logika Fuzzy untuk pendukung keputusan. Yogyakarta: Graha Ilmu, 2013.

[3] A. Heri and Darmawan Aan, Arduino Belajar Cepat Dan Pemrograman. Bandung: Informatika, 2015.

[4] L. Riadhi, M. Rivai, and F. Budiman, "Sistem Pengaturan Oksigen Terlarut Menggunakan Metode Logika Fuzzy Berbasis Mikrokontroler Teensy Board," J. Tek. ITS, vol. 6, no. 330-334, 2017.

[5] D. A. Rahman, M. Rivai, and R. Dikairono, "Sistem Navigasi Pada Balon Udara Menggunakan GPS dan Kontrol Logika Fuzzy," J. Tek. ITS, vol. 5, pp. A173-178, 2011.

[6] D. H. Fandiantoro, M. Rivai, and R. Dikairono, "Sistem Penjejak pada Balon Udara dengan Menggunakan Kamera dan Kotrol Logika Fuzzy," J. Tek. ITS, vol. 5, pp. A892-897, 2016.

[7] F. A. Muhammad, M. Rivai, and Suwito, "Perancangan Sistem Stabilisasi Kamera Tiga Sumbu dengan Metode Kontrol Fuzzy untuk Mobile Surveilance Robot," J. Tek. ITS, 2016.

[8] M. Rivai, K. Sambodho, and Dwi Purnomo H, "Identification of Levee Strength for Early Warning System Using Fuzzy Logic," in International Conference on Information, Communication Technology and System (ICTS), 2014.

[9] A. Thorat, S. Yadav, and S. Patil, "Implementation of Fuzzy Logic System for DC Motor Speed Control using Microcontroller," Int. J. Eng. Res. Appl., vol. 3, pp. 950-956, 2013.

[10] R. Aljabar, M. Rivai, and Suwito, "Rancang Bangun Omni untuk Mencari Sumber Gas Menggunakan Kontrol Logika Fuzzy Berbasis Mikrokontroler ARM STM-32," J. Tek. ITS, vol. 7, pp. 17-22, 2018. 